\title{
CONSIDERAÇÕES SOBRE A \\ CONSTRUÇÃO DE IDENTIDADE E \\ REPRESENTAÇÕES IDENTITÁRIAS EM \\ DUAS ADOLESCENTES MULTILÍNGUES - \\ ENTRE RÓTULOS E DIVERSIDADE
}

Nádia Cristina Dini ${ }^{1}$

Martha Gattarosa ${ }^{2}$

\begin{abstract}
RESUMO: A construção da identidade na pós-modernidade compreende a imagem de um sujeito em transformação, cujos aspectos controversos corroboram uma forma de composição de identificação peculiar. Aprender outras línguas e conviver com outras culturas constitui-se uma experiência que reflete nas formas de interação do sujeito com sua própria cultura e com a do outro, possibilitando uma construção de identidade. Ao analisar as narrativas de duas adolescentes bilíngues sobre as línguas e culturas que as constituem, observamos que a identidade não é fechada: ela está em constante movimento, mudança e negociação dentro do próprio discurso. O multilinguismo é assim marcado por aspectos culturais, sociais e emocionais na representação da identidade do sujeito ao realizar escolhas entre códigos culturais e linguísticos ligados a um traço identitário de percepção social ou comportamental.
\end{abstract}

PALAVRAS-CHAVE: bilinguismo; identidade.

\section{CONSIDERATIONS ON IDENTITY BUILDING AND REPRESENTATIONS IN TWO MULTILINGUAL ADOLESCENTS - AMONG LABELS AND DIVERSITY}

\begin{abstract}
Identity building in postmodernity brings to mind the image of someone going through transformation, whose controversial aspects corroborate a peculiar kind of identity composition, which involves different languages and cultures. Learning other languages is an experience that reflects on one's way of interaction both with their own culture and with the other's, as well as living in other cultures with different organizations. By analyzing the narratives of the two adolescents and the generations they constitute, the relationships between the people who are part of the set are in constant motion, are negotiated within the discourse itself. Multilingualism is stamped with cultural, social and emotional aspects in the subject's identity representation when they must choose cultural codes linked to an identity trace of social or behavioral perception.
\end{abstract}

KEYWORDS: bilingualism; identity.

1 Mestre em Filologia Românica - Ludwig-Maximilians-Universität München E-mail: nadia_dini@hotmail.com 2 Mestre em Applied languages pela University of Westminster(2008).E-mail: rosakatz@hotmail.com 


\section{Identidade transitória e sujeito bilíngue}

A construção da identidade na pósmodernidade compreende a concepção de um sujeito em transformação, que não conta mais com uma "identidade plenamente unificada, completa e coerente" (HALL, 2006, p. 13). O sujeito pós-moderno apresenta-se fragmentado em sua formação identitária, "composto não de uma única, mas de várias identidades, algumas vezes contraditórias ou não-resolvidas" (HALL, 2006, p.12). O ser humano é "visto como uma figura discursiva" (HALL, 2006, p.23) que se define continuamente ao longo de sua história, carregando as marcas de seu tempo e de suas vivências que variam nas relações estabelecidas, assim como frente a acontecimentos contemporâneos, em constante transformação e deslocamento.

Assumindo tal transitoriedade na constituição da identidade e seus aspectos controversos, deparamo-nos ainda com uma forma de composição de identificação peculiar que envolve diferentes línguas e culturas, assim como as diversas experiências e relações estabelecidas por sujeitos multilíngues em sua família e na sociedade de convívio. A experiência de aprender outras línguas provoca mudanças e engloba implicações nas formas de interação do sujeito com sua própria cultura e com a do outro. Da mesma forma, a convivência dentro de outras culturas e de modos de organização constituem uma maneira de ampliar o leque de possibilidades e de percepções possíveis para a realidade que vivenciam e para suas relações interpessoais, assim como expandem a compreensão e possibilitam alternativas para o agir.

\section{Definição e questionamentos sobre os sujeitos e sua(s) língua(s) e cultura(s)}

Observando a conjuntura da organização pósmoderna, e pensando nesse recorte específico de sujeitos que detém uma mobilidade aparentemente maior entre línguas e culturas, nos propusemos a examinar possíveis especificidades na construção de identidade e representações identitárias que poderiam existir nesse contexto próprio. $\mathrm{O}$ corpus deste trabalho é composto por relatos de duas adolescentes multilíngues em respostas redigidas a um questionário contendo sete perguntas abertas, com o intuito de promover ponderações sobre a própria identidade, sua constituição e as representações a respeito de si mesmo e do Outro, assim como em relação às línguas que falam e aos grupos que as constituem e aos quais se sentem pertencer. As perguntas elaboradas como disparadores para os relatos foram redigidas procurando clareza e simplicidade nos termos empregados, utilizando diferenciações e divisões coloquiais entre língua, cultura, identidade, para que estivessem próximo do uso e entendimento das entrevistas.

- Que línguas você fala?

- Que culturas você julga fazerem parte de sua identidade?

- Como você define cada uma dessas culturas?

- Quanto de você/qual parte sua você considera pertencer a cada uma delas?

- Você percebe alguma barreira ou conflito existente entre elas?

- O que é se sentir "em casa” para você em relação à nacionalidades que possui e aos países nos quais já viveu?

- Você acha que é diferente em relação a outras pessoas que não tiveram essa vivência? Em quais pontos?

Acreditando que, quando tratamos de identidade, falamos principalmente de um percurso biográfico, torna-se relevante contextualizar as vivências dos falantes que registraram suas impressões, opiniões e emoções em relação à sua própria história. Com base nisso, as entrevistadas deste ensaio foram identificadas pelas iniciais 
numeradas “G1", de 14 anos, e "G2”, de 17 anos, ambas bilíngues simultâneas (português-alemão) e bilíngues consecutivas (português-inglês).

Torna-se importante aclarar tal distinção entre os termos "bilinguismo simultâneo" e "bilinguismo consecutivo", visto que a idade de aquisição das línguas apresenta uma contribuição para outros aspectos de seu desenvolvimento, seja linguístico ou cognitivo, seja sócio-cultural, conforme nos aponta Megale, explicitando mais detalhadamente os critérios levados em consideração para realizar essa subdivisão dentro do bilinguismo infantil, que é a situação de nossas entrevistadas:

A idade de aquisição das línguas é considerada de extrema importância, pois afeta diversos aspectos do desenvolvimento do indivíduo bilíngue, como por exemplo: o desenvolvimento linguístico, neuropsicológico, cognitivo e sociocultural. De acordo com a idade de aquisição da segunda língua, dá-se o bilinguismo infantil, adolescente ou adulto. No infantil, o desenvolvimento do bilinguismo ocorre simultaneamente ao desenvolvimento cognitivo, podendo consequentemente influenciá-lo. O bilinguismo infantil subdividese: em bilinguismo simultâneo e bilinguismo consecutivo. No bilinguismo simultâneo, a criança adquire as duas línguas ao mesmo tempo, sendo exposta às mesmas desde o nascimento. Por sua vez, no bilinguismo consecutivo, a criança adquire a segunda língua ainda na infância, mas após ter adquirido as bases linguísticas da L1, aproximadamente aos cinco anos, conforme aponta Wei (2000). (MEGALE, 2015, p. 4)

A partir da entrevista, seguiram-se a análise das respostas e identificação de possíveis temas e conteúdos afins nos relatos redigidos visando explorar dados para a observação do processo de construção de identidade bilíngue das adolescentes que usam a língua alemã e a língua portuguesa cotidianamente em contexto familiar com a mãe, de nacionalidade brasileira, e com o pai, de origem austríaca. As mesmas perguntas foram aplicadas às duas entrevistadas, sem alteração do teor ou da ordem entre elas, para análise e comparação das semelhanças e diferenças entre as respostas. A partir destas foi possível tecer algumas reflexões a respeito da construção da identidade cultural de indivíduos bilíngues. Algumas respostas, embora redigidas a perguntas distintas, puderam ser agrupadas tematicamente pelo teor do seu conteúdo, sendo interessante notar a similaridade na percepção das duas irmãs na maior parte de suas observações sobre suas vivências, mesmo que tenham aparecido em diferentes momentos dos questionamentos, com lembranças ou impressões semelhantes ativadas por disparadores distintos.

A constituição identitária das adolescentes com as línguas portuguesa e a alemã se deu desde o nascimento em contextos de ordem familiar, social e escolar, porém, a exposição à língua alemã se deu unicamente pela influência paterna. Embora o dialeto austríaco seja a língua nativa do pai, ele nunca se comunicou com as adolescentes em dialeto, mas em "Hochdeutsch" (alemão padrão). A exposição ao dialeto foi vivida somente em momentos de passeios e estadia na casa dos avós paternos, que aconteciam de forma esporádica em férias ou posteriormente, por meios eletrônicos de comunicação. A escolha de utilizar a variante normativa da língua alemã foi baseada nas preferências da educação formal das escolas austríacas, feita somente em alemão padrão.

A aquisição da língua alemã em contexto familiar foi permeada com livros de leitura, músicas, jogos e filmes. As entrevistadas, na primeira infância, assistiam somente a filmes clássicos infantis em alemão e, por vezes, não sabiam a tradução em português de títulos como 'A Bela Adormecida' (Dornröschen), ou mesmo termos ou o nome de alguns alimentos. A comunicação entre os pais é feita em inglês, o que também garantiu a exposição a esse idioma durante a primeira infância, de forma passiva, sem uso ativo na fala ou na escrita por parte das entrevistadas. Mas foi durante a permanência de dois anos na Inglaterra que ambas as entrevistadas tiveram convívio com a língua inglesa e passaram a utilizá-la ativamente, tornando-se multilíngues. Desde o ingresso no ensino fundamental I até 
o presente momento, as entrevistadas cursaram escolas no Brasil. Nesse sentido, a experiência com a língua portuguesa formal é maior do que a com os outros dois idiomas, principalmente no aprendizado da língua segundo padrões normativos e convencionais, dentro do que é convencional nas instituições de ensino.

Quando questionadas sobre quais línguas falam, possibilitando que definissem seus limitações e domínios linguísticos próprios, nossas entrevistadas apresentaram o português, o inglês e o alemão, sendo que G2 ainda aponta uma quarta língua, enfatizando o processo de aprendizado da língua como uma "língua estrangeira", assim como uma consciência de suas habilidades em relação à mesma: "Estudei italiano por 2 anos. Não falo muito, mas entendo bastante."

\section{As línguas e a interação constituição da identidade}

Ao serem questionadas sobre a divisão e a representação dessas línguas e culturas em sua constituição identitária, ambas optaram por utilizar uma divisão numérica considerando a proporção de cada uma delas em sua formação, explicitando na resposta argumentos para suas justificativas:

$60 \%$ brasileira (por eu expressar meus sentimentos. Gosto de conversar muito e de estar perto das pessoas. Gosto muito do clima tropical, adoro praia sol e verão); $15 \%$ austríaca (é pouco, pois acho o austríaco reservado, e sou reservada); $25 \%$ inglesa (porque eu respeito muito o que o outro é, porque até me acho um pouco prepotente ou superior em algumas situações).

É interessante observar que nesse ponto G1 utiliza a primeira pessoa do singular para atribuir adjetivos qualitativos à sua identidade, mesmo que composta, suposta e subjetivamente, poridentidades diversas em suas origens linguísticas e culturais. Da mesma forma, G2 organiza seu sentimento de identidade numa divisão bastante próxima à de sua irmã, deixando de lado, entretanto, a sua vivência na Inglaterra, embora seja mais velha e tenha vivenciado mais tardiamente essa experiência:

Olha, se fosse colocar em porcentagem, diria que sou $60 \%$ austríaca e $40 \%$ brasileira. Embora eu valorize o lado afetivo, acolhedor, e a espontaneidade do brasileiro, eu acho importante levar em consideração o lado do respeito à individualidade e à introspecção do lado europeu. Eu acho importante ter esse lado mais racional. $\mathrm{O}$ brasileiro é muito passional.

G2 aponta, na forma de se relacionar, para a questão afetiva, que aparenta ser mais forte como característica do brasileiro: "O brasileiro é muito passional". O aparente excesso ("muito") pode ser considerado negativo e ela então enfatiza a busca por equilíbrio e harmonia com o "lado mais racional" do europeu, assim como "o respeito à individualidade" e "a introspecção", considerados características positivas nesse contexto.

Algumas representações expostas nos relatos apontam para representações e rótulos preconcebidos a respeito das línguas e culturas envolvidas, ao mesmo tempo que pontuam tolerância, aceitação e naturalização da diferença, da diversidade, da própria existência de um Outro em si que não é como ele e que tem sua existência aceita, afirmada e validada. Algumas opiniões dos enunciados parecem ser habituais e frequentes em imagens e representações já difundidas sobre determinados povos e culturas, algo comum na constituição de nossos conceitos a respeito de nós mesmos e do outro, ao longo do tempo, mesmo que de forma silenciada, apagada, sem consciência de tal processo de construção, como também nos aponta Coracini:

(...) o que somos e o que pensamos ver está carregado do dizer alheio, dizer que nos precede ou que precede nossa consciência e que herdamos, sem saber como nem por quê, de nossos antepassados ou daqueles que parecem não deixar rastros. $O$ que somos e o que vemos está carregado, portanto, do que ficou silenciosamente abafado na memória discursiva, como um saber anônimo, esquecido. (CORACINI, 2015, p. 202) 
Do mesmo modo, percebemos que no contraste entre as culturas aparecem algumas características que fazem parte do imaginário subjetivo que envolve cada uma delas. Por meio das respostas obtidas, podemos notar alguns recortes discursivos desses sujeitos multilíngues a respeito da própria singularidade biográfica e constatar algumas formas de reflexão sobre o processo constitutivo de suas identidades. Procuramos categorizar tais declarações e narrativas por temas similares, mesmo que não tenham sido registrados como respostas a uma mesma pergunta.

Um dos aspectos marcantes presentes nas respostas aponta para as formas de comunicação diferenciadas nas línguas e culturas em questão, formas estas que não se dissociam. Assim, apresentam-se descrições de algumas formas de falar (brasileiro) e formas de silenciar (austríaco) que fazem parte do repertório de interação social dos sujeitos, como relata G2:

\begin{abstract}
O fato de eu ser reservada faz eu me sentir mais austríaca, não gosto de ser pegajosa. Meus amigos sempre chegam "causando", gritando e se pendurando. Embora eu seja reservada, eu tenho um lado brasileiro em demonstrar sentimentos, do tipo dizer "EU TE AMO", "MUITAS SAUDADES". Vejo que minhas primas austríacas não postam tanto no Instagram ou Face muitas fotos com as amigas expressando sentimentos como eu faço aqui. Acho que meu lado brasileiro é ser mais franca em dizer o que sinto.
\end{abstract}

As formas de comunicação retratadas na percepção presente nesse relato apontam para comunicações verbais ("gritar”, "expressar", "dizer o que sente") e não verbais ("se pendurar") que se configuram como características típicas do que seria "ser brasileiro", expressões estas que apontam para uma extroversão mais ampla em relação à manifestação de sentimentos e opiniões. As redes sociais digitais, como Instagram e Facebook, e a frequência na partilha de vivências aparecem também como indícios comunicativos diferenciais entre as culturas comparadas e confrontadas, como mais uma fonte de exposição e comunicação de ideias e sentimentos. Assim, vemos que a identificação com pontos específicos de cada cultura vai muito além da língua e se engendra por nuances de comportamento, de convenções sociais, de formas de relacionar-se, de comunicar-se, de negociar sentidos nos enunciados e também nas interações. Tal sistema de interação é complexo e pode acarretar conflitos, apresentando consequências em sua (in)adequação entre os diferentes sistemas válidos nas línguas e culturas em negociação:

Essa identificação e diferenciação não podem
ser apreendidas à margem dos sistemas
de significação social vigentes. Sobre esse
aspecto, vale ressaltar que ter características
e comportamentos apontados pela sociedade
como indesejáveis pode suscitar sanções e
reprimendas, o que remete à ideia de que a
construção da identidade não ocorre de forma
harmoniosa ou equilibrada, mas é fruto de um
jogo de poderes, em que a dominância dos
grupos hegemônicos aponta o socialmente
valorizado e influencia a constituição da
identidade. (MEGALE, 2012, p.4)

Dessa forma, a identificação com a cultura europeia/austríaca na maneira de se relacionar mais comedida do que a apontada sobre os brasileiros pode influenciar o convívio e os vínculos estabelecidos no meio social, como ser mais "reservada" que o grupo de amigos ou se sentir incomodada com uma relação "pegajosa" ou comportamentos que importunam como "gritar" e "se pendurar", conforme exemplos relatados por G2.

Embora algumas perguntas presentes na entrevista-questionário apontem para uma diferenciação e uma segmentação das línguas e culturas envolvidas, é interessante observar que as entrevistadas passam a utilizar a terceira pessoa do plural para identificar e definir características de um ou outro povo, como se não fizessem parte de sua própria constituição. Nesse ponto, percebemos a reprodução e o reforço de algumas ideias sobre o 
que é diferente, tomando o outro como referência, como parâmetro de contraste nas definições. Tais enunciados apresentam pontos de superioridade em relação a alguns aspectos marcados por adjetivos valorativos, julgando as diferentes características, comparando-as e categorizando em definições positivas ou negativas.

Dessa forma, o Outro passa a ser um estrangeiro, seja ele brasileiro, austríaco ou inglês, dependendo do deslocamento que os sujeitos realizam e do lugar que ocupam ou tentam ocupar dentro de sua própria identidade. Segundo Coracini, o Outro estrangeiro está presente em nosso discurso e nos constitui:

\begin{abstract}
Partindo do pressuposto extraído da psicanálise lacaniana e das teorias do discurso segundo o qual o outro nos constitui assim como constitui o nosso discurso, é possível afirmar que as representações que fazemos do estrangeiro $e$ as representações que o estrangeiro faz de nós atravessam, de modo constitutivo, o sentimento de identidade subjetiva, social e nacional. (CORACINI, 2015, p. 201)
\end{abstract}

G1 apresenta o brasileiro como "sentimental, curte e vive muito intensamente. Fala alto, é muito latino. Gosta de festa e causa." Já G2 aponta alguns adjetivos que definiriam esse povo de uma maneira geral como "acolhedor, animado, expansivo, extrovertido e afetuoso.” Os austríacos, por sua vez, recebem de G1 descrições de "muito reservado, algumas vezes frio", enquanto G2 os considera um povo "reservado, respeita a individualidade e o espaço pessoal do outro. Acho que são introspectivos e pontuais. Planejam tudo com antecedência.” G1 ainda apresenta sua versão sobre os ingleses: "acho eles prepotentes, acham que são o centro do mundo.” Essa constatação parece ter como base uma experiência pessoal envolvendo o desempenho linguístico da mãe, julgado e depreciado por não corresponder ao de um falante nativo. A marca de episódio parece ter influenciado diretamente na percepção e representação da cultura e do país: "Convivi com ingleses em uma vila no longe de Londres, não tinha muito estrangeiro, e percebi que quando minha mãe falava inglês e o sotaque dela não fosse como "British" sentia que eles olhavam de lado."

Como forma de valorizar ou criticar cada uma das culturas, predomina a maneira como cada um interage e se relaciona com o outro no cotidiano. A mesma característica, no entanto, pode aparecer como positiva ou negativa pelos sujeitos dos relatos ou pela mesma entrevistada em diferentes momentos. Assim, ser "reservado" aparece para G2 como algo positivo, de alguém que sabe respeitar o outros em seu espaço e em sua singularidade. Já para G1, tal característica é algo forte no povo austríaco ("muito") e tende a um significado negativo, pois denota frieza na forma de se relacionar com as demais pessoas, contrastando com o lado sentimental do brasileiro, definido por ela. G2 apresenta um contraponto do brasileiro em relação ao austríaco também na forma relacional e de interação, porém, esse contraponto, embora apresente características possivelmente opostas, é também apresentado de maneira positiva como "acolhedor" e "afetuoso". Assim, embora as características de cada um pareçam se excluir mutuamente, sem formas de conciliação, são valorizadas em suas peculiaridades, como aspectos de cada cultura que destoam uma da outra, mas que contém em si uma perspectiva assertiva sobre a forma de cada ser, constituir-se e relacionar-se, mesmo que dentro de preconcepções conhecidas e compartilhadas no discurso do senso comum sobre os povos em questão.

\section{Identificações, tensões e tolerância}

Nas definições encontradas ao longo das respostas, percebemos um deslocamento entre dois pontos, muitas vezes opostos, ao enaltecer e ao criticar caraterísticas de cada cultura, por 
meio de pronomes pessoais utilizados na primeira pessoa do singular ou do plural, de acordo com a identificação positiva da qual pretende apropriar-se como parte de sua própria identidade, ou negativa, quando deseja distanciar-se do que seria a cultura do outro, sem reconhece-la como sua ou como parte de si. Tal movimento contínuo, de idas e vindas, é permeado por oposições, incompatibilidades e até de inquietações, como nos aponta Coracini:

É nessa região de conflitos e tensões - entre a extrema valorização do outro, da cultura e da língua do outro e a extrema valorização da própria cultura e, consequentemente, entre a desvalorização da própria cultura e a desvalorização do outro -, onde se dá o deslizamento de sentidos, que se configura a subjetividade e a identidade do sujeito e da nação e, portanto, do brasileiro e do Brasil. (CORACINI, 2015, p. 218)

As mudanças provocadas pelo deslocamento espacial e cultural de quem vive e convive com mais de uma língua/cultura provocam, de certa maneira, conflitos nos indivíduos. Há sempre um viver "entre", um "meio termo", na forma como essa experiência subjetiva (BUSCH, 2015, p.3) os afeta. Assim, demarcar qual cultura pode definir tais sujeitos e de qual forma, perpassa também o sentimento de pertencer a algo ou a algum lugar, num processo fluido e híbrido que está sempre em movimento, sempre sendo construído, entre caminhadas e retornos.

Nos relatos, parece mesmo não haver escolhas possíveis entre esta e aquela cultura, entre este e aquele lugar, uma caminhada marcada por percursos de movimento constante. Assim nos relata $\mathrm{G} 1$ em sua narrativa, frisando a falta que sente do que está longe e percebendo a ausência de vínculos com outras pessoas como determinante para sentir-se em casa no Brasil e não na Áustria:

Minha casa é aqui no Brasil. Aqui tenho minha rotina, meus amigos. Eu tenho minha família na Áustria, mas não tenho laços de amigos de infância. Mas sinto muita falta de lá: da casa da minha vó, do cheiro da neve e da comida.
Percebemos como os laços afetivos e as relações interpessoais (amigos, família), além de certo saudosismo relacionado às lembranças de infância, surgem como parte das lembranças e da falta, da impossibilidade de confluência de tais aspectos dentro do mesmo tempo e espaço. No entanto, a duração ou extensão de tempo vivenciado em um mesmo lugar, parece determinar a identificação relatada por G2:

\begin{abstract}
Decidir onde me sinto em casa me deixa um tanto quanto dividida, querendo ou não as duas nacionalidades fazem parte de quem eu sou. Mas, considerando que toda a minha rotina, amigos e estudos estão aqui, eu diria que é no Brasil que eu me sinto mais em casa.
\end{abstract}

A organização da rotina e a instituição escolar citadas por ela constituem outro aspecto ligado ao "sentir-se em casa", pois determinam grande parte da vida da adolescente nesse momento específico de sua vida. A experiência de viver entre culturas, seja ou não em território físico e as fronteiras marcadas por elas, provoca mudanças de perspectiva na forma de perceber e de contemplar o mundo exterior. Busch nos assinala possibilidades e desafios que se abrem quando sujeitos (con)vivem com mais de uma língua ou cultura, oportunizando a abertura de novas perspectivas:

Relocating the center of one's life, either within
a country or from one country or continent
to another, always means a change, both in
the life world (Lebenswelt) which provides an
inter-subjective pool of perceiving, and in
the linguistic environment where practices,
discourses and rules are familiar. Under
favourable conditions, this kind of change can
be experienced as a challenge, opening up new
horizons and new opportunities to re-invent
oneself as a (speaking) subject. (BUSCH,
2015, p. 2)

3 Realocar o centro da vida de alguém, seja no mesmo país, seja em outro país ou continente, sempre significa mudança, tanto nos ambientes da vida (Lebenswelt), que oferecem um leque intersubjetivo de percepções, quanto no ambiente linguístico onde as práticas, discursos e regras são familiares. Sob condições favoráveis, esse tipo de mudança pode ser experienciado como um desafio que mostre novos horizontes e oportunidades para que a pessoa se reinvente como sujeito falante. (tradução das autoras) 
Algumas vezes, tais transformações são constatadas pelo próprio falante em relação aos demais indivíduos com os quais se relaciona, e podem ser sentidas como positivas ou negativas, ou mesmo de ambas as formas ao mesmo tempo. Nesse aspecto, G1 analisa as diferenças percebidas por ela na constituição de sua identidade em relação aos amigos que não tiveram a mesma experiência de crescer e conviver com outras línguas culturas desde a primeira infância, nem de se contrapor à sua própria cultura em um outro país com distanciamento e colocando-se em outra perspectiva:

Eu vejo sim. Vejo o mundo de outra forma, lido com os problemas de forma diferente. Eles muitas vezes falam de outros países de maneira preconceituosa. Sem conhecer sabe, daí penso como podem falar de uma coisa que não viveram?

A tolerância e o respeito à diversidade aparecem como ponto constituinte de sua identidade a partir de sua vivência em outro país e com outra(s) cultura(s), não necessariamente originárias do país de moradia, mas em relação às diferentes manifestações culturais e hábitos (co) existentes, sejam estes de pessoas da mesma origem geográfica ou linguística ou de proveniências distintas entre si:

Vi na Inglaterra uma variedade de pessoas e religiões. Antes nunca tinha visto burca ou mulçumanos onde moro. Vi punks e aprendi a respeitar muito o outro. Sinto isso diferente, pelo menos dos meus amigos que julgam muitos os outros. Ver várias raças (multicultural) me fez ver todos devem ser respeitados pelas diferenças.

Da mesma forma, sua irmã G2 considera que a influência de crescer em mais de uma cultura, seja no ambiente doméstico e familiar, seja nos ambientes escolar e social, pode conduzir para uma outra concepção nos relacionamentos interpessoais e na maneira de analisar o mundo que a cerca:
[...] me sentir parte de mais de uma cultura me ajuda muito a interpretar uma mesma situação de formas diferentes. Acho interessante ter mais de uma forma de ver as coisas, no momento de tomar decisões faz bastante diferença. (...) Eu acho que qualquer oportunidade de viver com outras culturas conta muito para entender as diversidades e aumenta bastante o repertório de vida. Sinto bastante diferença em relação aos meus amigos, sim, principalmente em relação à diversidade. Qualquer um que tenha gostos fora do que eles consideram "normal" é motivo para julgamento. Ter vivido na Inglaterra durante um ano e meio me ajudou muito a entender e respeitar a diversidade, acho que para muitos ainda falta um pouco disso.

Para ambas as entrevistadas, o deslocamento físico, a distância estabelecida entre o país de origem e o país estrangeiro, parece ter sido determinante para a construção de uma compreensão do outro e de si, mais até do que a vivência bilíngue português- alemão. Talvez por essa já constituir-se com naturalidade no ambiente familiar, como parte inerente de sua experiência de vida, sem se perceber a todo momento como culturas contrapostas ou distintas em aspectos linguísticos ou interacionais. Talvez o domínio maior do português e do alemão contribuam também para uma identificação mais fluida com tais culturas, reconhecendo-as como parte de si e de sua identidade de maneira incorporada, enquanto a vivência em outro país e com outra língua tenha provocado um estranhamento e, portanto, um distanciamento maior, responsável por acrescentar outros pontos à construção da identidade dos sujeitos, como tolerância ao que é distinto do que somos.

\section{Considerações Finais}

Percebemos como tais vivências entre culturas e línguas, na forma de bilinguismo no ambiente familiar ou na experiência de residir em outro país, provocam mudanças na constituição do sujeito ao considerar diversos aspectos de uma mesma situação. Vivenciar o Outro por meio de sua língua e sua cultura pode ensinar sobre a 
diversidade de pontos de vista, sobre a variedade nos modos de ser e de viver, ampliando o repertório de possibilidades de compreender o mundo em suas aparentes incongruências culturais. É uma marca significativa na constituição do indivíduo, de sua identidade e da sua forma de se relacionar com os outros e experenciar a realidade que o cerca, analisando de forma distinta os acontecimentos que observa.

O exercício desta análise nos faz concluir que a experiência relacionada ao multilinguismo é marcada por aspectos culturais e sociais com viés afetivo na representação da identidade do sujeito que realiza escolhas constantes em deslocamentos entre os códigos culturais que encontram-se atrelados a um traço identitário de percepção social ou comportamental.

Observamos pelo discurso desses sujeitos que a identidade não é fechada, está em constante movimento e mudança. É um processo de formação conflituoso que engloba experiências singulares ao mesmo tempo em que se apropria do discurso vigente, reproduzindo representações, ideias e imagens pré-concebidas sobre diferentes culturas e seus falantes. Esse processo possibilita aos falantes reconstruírem-se constantemente aproximando-se ou distanciando-se das diferentes representações sociais. O sujeito multilíngue é marcado por tal movimento entre culturas que tornam sua identidade ainda mais fluida. Esse deslocamento é influenciado por necessidades de se aproximar ou de se afastar de características atribuídas a esta ou àquela cultura, dependendo da posição que o sujeito deseja tomar para si em determinada situação, diferenciando-se em seu discurso sobre si e sobre o outro e, por vezes, reiterando rótulos já existentes.

\section{REFERÊNCIAS}

BUSCH, B. Linguistic repertoire and Spracherleben, the lived experience of language. Working Papers in Urban Language \& Literacies. King's College London, 2015. Disponível em: <https:// www.kcl.ac.uk/ecs/research/research-centres/ ldc/publications/workingpapers/abstracts/ wp148-busch-2015--linguistic-repertoire-andspracherleben,-the-lived-experience-of-language $>$ Acesso em 29 de julho de 2019.

CORACINI, M. J. A Celebração do Outro na constituição da identidade, 12/2003, Organon (UFRGS), Vol. 9, pp.134-148, Porto Alegre, RS, BRASIL, 2003. Disponível em: <https://seer. ufrgs.br/organon/article/view/30024> Acesso em 29 de julho de 2019.

HALL, S. A identidade cultural na pósmodernidade. Rio de Janeiro: DP\&A Editora, 1992, 11ª edição.

MEGALE, A. Bilinguismo e educação bilíngue discutindo conceitos. Revista Virtual de Estudos da Linguagem - ReVEL. V. 3, n. 5, agosto de 2005. Disponível em: <http://www.revel.inf.br/ files/artigos/revel_5_bilinguismo_e_educacao_ bilingue.pdf $>$. Acesso em 29 de julho de 2019.

.ParaAlémdaLinhadoTrem:Histórias

Sobre Línguas e Estigma. III Simpósio Nacional Discurso, Identidade e Sociedade. Dilemas e Desafios na Contemporaneidade. Campinas: Unicamp, 2012. Disponível em: <https://www. academia.edu/13100429/PARA_AL\%C3\%89M_ DA_LINHA_DO_TREM_HIST $\%$ C3\%93RIAS_ SOBRE_L\%C3\%8DNGUAS_E_ESTIGMA $>$. Acesso em 29 de julho de 2019.

Submissão: julho de 2019. Aceite: janeiro de 2020. 